\title{
Absence of Smoker's Paradox in Middle Eastern Patients with Acute Coronary Syndrome
}

Saleh $A^{*}$

Faculty of medicine, University of Jordan, Jordan

\begin{abstract}
Studies have shown that smokers admitted with acute coronary syndrome (ACS) have an apparent lower inhospital and long term mortality rates compared with nonsmokers ("smoker's paradox"). This study was done to test if the "smoker's paradox" exists in Middle Eastern ACS patients. A 1618 consecutive patients admitted with acute coronary syndrome in 4 tertiary hospitals were enrolled. We compared clinical and coronary angiographic features and mortality during admission and after one year among smokers vs. non-smokers. Of the whole group $(\mathrm{N}=1618)$; smokers ( $\mathrm{N}=859 ; 53 \%)$ were younger than non-smokers (Mean age $50+7$ vs. $63+9$ year; $\mathrm{P}=0.005$ ), more likely to be male $(96 \%$ vs. $69 \%$; $\mathrm{P}<0.001)$, and less likely to have hypertension $(33 \%$ vs. $67 \%$; $\mathrm{P}<0.001)$ and diabetes mellitus $(29 \%$ vs. $50 \%$; $P<0.001)$. Smokers were more likely to have ST-segment elevation myocardial infarction (STEMI) than non-smokers ( $35 \%$ vs. $24 \%$; $\mathrm{P}<0.001)$ and less likely to have non ST-segment elevation ACS $(65 \%$ vs. $76 \%$; $\mathrm{P}=0.005)$. Compared with non-smokers; smokers had similar incidence of anterior wall MI ( $51.7 \%$ vs. $53.9 \% ; P=N S)$, higher incidence of single vessel disease $(54 \%$ vs. $47 \%$; $P=0.002)$ and lower incidence of multi vessel disease ( $44 \%$ vs. $51 \% ; P=0.005)$. There were no statistically significant differences between the in-hospital $(3.2 \%$ vs. $2.2 \%$; $=0.29)$ and 1 -year $(6.5 \%$ vs. $7.0 \% ; P=0.92)$ mortality rates in smoker sand non-smokers; respectively. Despite being younger with less prevalence of comorbid diseases, multivessel coronary artery disease, and low TIMI risk scores; smokers in the Middle East with ACS did not have a better in-hospital or 1 year out come compared with nonsmokers.
\end{abstract}

Keywords: Non-smokers; Atherosclerotic; Coronary artery

Angiographic;

Hypertension;

\section{Introduction}

Cigarette smoking is a well-established modifiable risk factor for atherosclerotic coronary artery disease (CAD) [1-3]. It is known for its role in impairing endogenous fibrinolysis, enhancing platelet aggregation and thrombus formation, and promoting the development of a thin fibrous cap in atherosclerotic coronary plaques, thus predisposing the plaque to erosion and subsequent thrombosis leading to acute coronary syndrome (ACS) [4-7]. However, various studies have shown that smokers have lower mortality rates following ACS than non-smokers, suggesting that smoking has a protective effect in ACS giving rise to the concept of the "smoker's paradox", in which smokers are more likely to suffer ACS but also more likely to survive [8-10]. Subsequently, various studies have demonstrated that smokers tended to be younger, with fewer comorbidities, and less extensive coronary disease. These differences were suggested to explain the difference in mortality [11-16]. According to data from Jordanian and regional studies, patients with ACS are an average 10 years younger than those in developed countries and have high prevalence of smoking [17-19]. However, the "smoker's paradox", has not been evaluated in patient with ACS in the Middle East before. We therefore undertook this study to examine the clinical characteristics, presentation, in-hospital treatment, angiographic features, prognosis, and the in-hospital and one-year mortality of patients with and without a history of smoking admitted with ACS.

\section{Method}

A 1618 consecutive patients admitted with acute coronary syndrome in 4 tertiary hospitals were enrolled. We analyzed the clinical characteristics, coronary angiographic findings, risk stratification and mortality during admission and after one year among smokers and non-smokers. The whole group included 759 smokers and 859 non- smokers. Inclusion criteria included: adults $\geq 18$ years of age admitted with ACS and agreeing to sign an informed consent to be enrolled in the study. Exclusions criterion was refusal to sign the consent. Smoking was defined as current cigarette smoking at the time of enrollment. ACS was classified as (1) STEMI defined by the presence of typical chest pain suggestive of myocardial ischemia associated with ST-segment elevation of $\geq \mathrm{mm}$ in at least 2 contiguous leads on the 12-lead electrocardiogram (EKG), and elevated cardiac troponin T or CPK-MB ( $\geq 2$ upper limit of normal for both tests), (2) Non ST-segment elevation ACS (NSTACS) was diagnosed as either NSTEMI or unstable angina (UA). NSTEMI was defined by the presence of typical chest pain and ST-segment depression, inverted $\mathrm{T}$ wave or normal EKG and elevated cardiac troponin T or CPK-MB ( $\geq 2$ upper limit of normal for both tests), or unstable angina (UA) defined by the presence of typical chest pain and ST-segment depression, inverted $\mathrm{T}$ wave or normal EKG and normal cardiac enzymes on admission and 8-12 hours later. Diabetes mellitus (DM) was defined as known history of the disease made by a physician, or patient using antidiabetic treatment. Hypercholesterolemia was defined as fasting serum total cholesterol level $\geq 240 \mathrm{mg} / \mathrm{dl}$ or using hypolipedemic agents. Obesity was defined as a body mass index $\geq 30$ $\mathrm{kg} / \mathrm{m}^{2}$. Left ventricular (LV) systolic function was assessed by contrast ventriculography or 2-D echocardiography and was considered normal

*Corresponding author: Saleh A, Associate Professor, Faculty of Medicine, University of Jordan, Jordan, Tel: 009626 5353444; E-mail: a.saleh@ju.edu.jo

Received October 18, 2016; Accepted October 20, 2016; Published October 25, 2016

Citation: Saleh A (2016) Absence of Smoker's Paradox in Middle Eastern Patients with Acute Coronary Syndrome. J Vasc Med Surg 4: 290. doi: 10.4172/23296925.1000290

Copyright: (C) 2016 Saleh A. This is an open-access article distributed under the terms of the Creative Commons Attribution License, which permits unrestricted use, distribution, and reproduction in any medium, provided the original author and source are credited. 
when the LV ejection fraction was $\geq 50 \%$. Patients were treated according to the discretion of the treating physician by conservative or invasive strategy. The TIMI risk score in each of the 502 patients with NSTEACS was determined by the sum of the presence of 7 variables at admission; 1 point was given for each of the following variables: age $\geq 65$ years; $\geq 3$ coronary artery disease (CAD) risk factors; past history of CAD $(\geq 50 \%$ stenosis); ST segment deviation; use of aspirin in the prior 7 days; $\geq 2$ episodes of angina in the past 24 hours; and elevated serum cardiac biomarkers.12 Scores were classified as low (0-2 points), intermediate (3-4 points), or high ( $\geq 5$ points). The TIMI risk score in each of the 265 patients with STEMI was computed by the sum of points (total of 1314 ) of the following variables: age $\geq 75$ years ( 3 points) or $56-74$ years ( 2 points); presence of diabetes mellitus, hypertension or angina (1 point); systolic blood pressure $<100 \mathrm{~mm} \mathrm{Hg}$ ( 3 points); heart rate $\geq 100$ beats per minute ( 2 points); Killip class II-IV ( 2 points); weight $<67 \mathrm{~kg}$ (1 point); anterior ST elevation or left bundle branch block (1 point); and time to reperfusion therapy $\geq 4$ hours ( 1 point). 13 Scores were classified as low (0-3 points), low intermediate (4-6 points), high intermediate (7-9 points), or high ( $\geq 10$ points). Coronary revascularization (percutaneous or surgical) was undertaken depending on the severity and complexity of the coronary disease and comorbid diseases. Demographic, clinical, laboratory, echocardiographic and angiographic data were collected. Incidence of clinical events during hospitalization (cardiac death, ventricular tachycardia or fibrillation, heart failure, bleeding and stroke) and the 1-, 6- and 12-month mortality rates were compared between smokers and non-smokers The main outcome analyzed was overall mortality during hospital stay and one year. One year follow-up was achieved in all of the patients, through clinic consultation or telephone contact. The study protocol was approved by the ethics committees of the participating hospitals.

\section{Statistical Analysis}

The chi-square test was used to compare categorical variables, expressed as percentages and frequency. Continuous variables, expressed as means \pm standard deviation, were compared using the Student's $t$ test for those with a normal distribution, or the MannWhitney test otherwise. Multivariate logistic regression analysis was used to identify variables independently associated with smoking, as well as independent predictors of in-hospital and 12-month mortality. A value of $\mathrm{P}<0.05$ was considered statistically significant.

\section{Results}

Baseline clinical and coronary angiographic characteristics of the patients are shown in Table 1 . Smokers were younger and more frequently male, and less often had diabetes and hypertension $(\mathrm{P}<0.001)$. They also less often had a positive family history of IHD and aspirin use prior to ACS $(\mathrm{P}<0.05)$, with no statistically significant differences with regard to other cardiovascular risk factors. Patients with smoking history more frequently presented with ST elevation and were less frequently in NSTEACS $(\mathrm{P}<0.05)$. The incidence of anterior wall MI and impaired left ventricular systolic function was similar in the two groups (51.7\% vs. $53.9 \%, \mathrm{P}=\mathrm{NS}$ ). The clinical variables showing statistically significant differences between the two groups were included in a logistic regression multivariate analysis in order to identify independent associations between these variables and smoking. This showed that age (odds ratio $[\mathrm{OR}]=0.96 ; 95 \%$ confidence interval $[\mathrm{CI}]: 0.940 .98 ; \mathrm{P}<0.001$ ), diabetes $(\mathrm{OR}=0.58$; 95\% CI: $0.38-0.89 ; \mathrm{P}<0.001)$ and $\mathrm{HT}(\mathrm{OR}=0.52 ; 95 \%$ CI: $0.37-0.75 ; \mathrm{P}<0.001)$ were independently and negatively associated with smoking, while male gender $(\mathrm{OR}=15.50$; 95\% CI: $7.82-30.70$; $\mathrm{P}<0.001)$ was independently and positively associated.
In Table 2 shows the TIMI risk scores in patients with NSTEACS and STEMI at admission according to smoking status. High TIMI risk scores in patients with non ST elevation ACS were less prevalent in smokers compared with nonsmokers $(60 \%$ vs. $75 \%, \mathrm{P}=0.003)$. In STEMI patients, high TIMI scores occurred similarly in smokers and nonsmokers ( $11.1 \%$ vs. $9.8 \%, \mathrm{P}=0.201)$.

Angiographic and echocardiographic data, are shown in Table 3. Coronary stenosis of $\geq 50 \%$ was considered significant disease. Of those undergoing coronary angiography, patients with a history of smoking had higher incidence of single vessel disease and less incidence of proximal left anterior descending (LAD), left main (LM), or multivessel CAD.

Treatment strategies are shown in Table 4. During hospital stay and on discharge, smokers and non-smokers were medicated with Standard

\begin{tabular}{|c|c|c|c|}
\hline & Smokers & Non-smokers & Significance \\
\hline N (\%) & $756(46.8 \%)$ & $859(53.2 \%)$ & \\
\hline Age (mean) & 50 & 63 & $\mathrm{p}<0.001$ \\
\hline Male & $688(91 \%)$ & $567(66 \%)$ & $\mathrm{p}<0.001$ \\
\hline Diabetes & $144(19 \%)$ & $378(44 \%)$ & $\mathrm{p}<0.001$ \\
\hline Hypertension & $401(53 \%)$ & $576(67 \%)$ & $\mathrm{p}<0.001$ \\
\hline Family history of CHD & $83(11 \%)$ & $155(18 \%)$ & $\mathrm{p}=0.009$ \\
\hline Dyslipidemia & $431(57 \%)$ & $550(64 \%)$ & $\mathrm{ns}$ \\
\hline Obesity & $265(35 \%)$ & $318(37 \%)$ & $\mathrm{ns}$ \\
\hline Past Cardiovascular history & $91(12 \%)$ & $112(13$ & $\mathrm{ns}$ \\
\hline Prior Aspirin & $325(43 \%)$ & $462(54 \%)$ & $\mathrm{p}-0.004$ \\
\hline Prior angina & $76(10 \%)$ & $120(14 \%)$ & $\mathrm{ns}$ \\
\hline Presentation & & & $\mathrm{p}=0.01$ \\
\hline STEMI & $265(35 \%)$ & $206(24 \%)$ & $\mathrm{P}=0.03$ \\
\hline NSEMI & $174(23 \%)$ & $258(30 \%)$ & $\mathrm{P}=0.01$ \\
\hline UA & $318(42 \%)$ & $395(46 \%)$ & \\
\hline
\end{tabular}

ns: non-significant; CHD: Coronary heart disease; STEMI: ST-Segment Elevation Myocardial Infarction; NSEMI: Non-ST-Segment Elevation Myocardial Infarction.

Table 1: Baseline clinical characteristics stratified by smoking status at the time of admission.

\begin{tabular}{|c|c|c|c|}
\hline ACS & Smoker & Non-smoker & p value \\
\hline NSTEACS & $492(\%)$ & $653(\%)$ & \\
\hline Low score & $195(39.6 \%)$ & $166(25.4 \%)$ & 0.003 \\
\hline Intermediate score & $203(41.2 \%)$ & $295(45.2 \%)$ & 0.003 \\
\hline High score & $94(19.2 \%)$ & $192(29.4 \%)$ & 0,003 \\
\hline STEMI & $265(\%)$ & $206(\%)$ & \\
\hline Low score & $171(64.4 \%)$ & $107(51.9 \%)$ & 0,03 \\
\hline Low intermediate score & $85(32.2 \%)$ & $97(46.9 \%)$ & 0.004 \\
\hline High score & $9(3.4 \%)$ & $2(1.2 \%)$ & $n s$ \\
\hline
\end{tabular}

Table 2: TIMI risk scores at admission among patients with acute coronary syndrome.

\begin{tabular}{|c|c|c|c|}
\hline & Smokers & Non-smokers & Significance \\
\hline $\mathrm{N}$ & $756(46.8 \%)$ & $859(53.2 \%)$ & - \\
\hline Aspirin & $748(99 \%)$ & $851(99 \%)$ & $\mathrm{ns}$ \\
\hline Clopidogrel & $529(70 \%)$ & $653(76 \%)$ & $\mathrm{ns}$ \\
\hline Heparin & $748(99 \%)$ & $851(99 \%)$ & $\mathrm{ns}$ \\
\hline B-blocker ns & $272(36 \%)$ & $326(38 \%)$ & $\mathrm{ns}$ \\
\hline Statins & $643(85 \%)$ & $713(84 \%)$ & $\mathrm{ns}$ \\
\hline PCI & $348(46 \%)$ & $412(48 \%)$ & $\mathrm{ns}$ \\
\hline CABG & $18(2.4 \%)$ & $28(3.3 \%)$ & $\mathrm{ns}$ \\
\hline Reintervention & $1(0.001 \%)$ & $3(0.003 \%)$ & $\mathrm{ns}$ \\
\hline
\end{tabular}

LAD: Left Anterior Descending; LVF: Left Ventricular Function; ns: Non-Significant.

Table 3: Angiographic characteristics of smokers and non-smokers. 
cardiovascular medications (aspirin, beta blockers, renin-angiotensin system blockers, statins and heparin) with no statistically significant differences. Diagnostic coronary angiography and revascularization procedures using percutaneous intervention or surgical bypass were used in similar frequencies in both the groups.

On univariate analysis, patients with a history of smoking had numerically higher in-hospital mortality and lower one year mortality although this did not reach statistical significance $(3.2 \%$ vs. $2.2 \%$; $\mathrm{P}=0.4),(6.5 \%$ vs. $7.8 \% ; \mathrm{P}=0.4)$ respectively. However, after adjustment for variables with prognostic impact (age, left ventricular dysfunction, TIMI risk scores, diabetes and gender), smoking was not associated with better one year prognosis.

Except for heart failure; which was less frequent in smokers; other in-hospital complications (bleeding, stroke and ventricular tachyarrhythmia's) occurred in similar frequency in both groups. Mortality among smokers was not different from non-smokers during hospitalization, after 1, 6, and 12 months of follow up. In Table 5 shows the in-hospital complications and mortality.

\section{Discussion}

To our knowledge; this is the first study that evaluated the potential presence of smoker's paradox in patients admitted with ACS in the Middle East. Despite being younger and having less prevalence of comorbid disease or LV systolic dysfunction, less prevalence of high TIMI risk scores, less prevalence of multivessels, proximal LAD or LM CAD; we have demonstrated that smoker's paradox does not exist in our patients. We did not demonstrate lower incidence of anterior wall MI or major in-hospital complications in smokers compared with nonsmokers. Furthermore and most importantly, smokers did not have a better survival rate during index admission or up to 1 year of follow up.

Cigarette smoking adversely affects the cardiovascular system through several mechanisms: arterial endothelium injury, low-grade

\begin{tabular}{|c|c|c|c|}
\hline & Smokers & Non-smokers & Significance \\
\hline $\mathrm{N}$ & $756(46.8 \%)$ & $859(53.2 \%)$ & - \\
\hline Aspirin & $748(99 \%)$ & $851(99 \%)$ & $\mathrm{ns}$ \\
\hline Clopidogrel & $529(70 \%)$ & $653(76 \%)$ & $\mathrm{ns}$ \\
\hline Heparin & $748(99 \%)$ & $851(99 \%)$ & $\mathrm{ns}$ \\
\hline B-blocker ns & $272(36 \%)$ & $326(38 \%)$ & $\mathrm{ns}$ \\
\hline Statins & $643(85 \%)$ & $713(84 \%)$ & $\mathrm{ns}$ \\
\hline PCl & $348(46 \%)$ & $412(48 \%)$ & $\mathrm{ns}$ \\
\hline CABG & $18(2.4 \%)$ & $28(3.3 \%)$ & $\mathrm{ns}$ \\
\hline Reintervention & $1(0.001 \%)$ & $3(0.003 \%)$ & $\mathrm{ns}$ \\
\hline
\end{tabular}

PCl: Percutaneous Intervention; CABG: Coronary Artery Bypass Graft; ns: Nonsignificant.

Table 4: Treatment strategies according to smoking status.

\begin{tabular}{|c|c|c|c|}
\hline & Smoker 756 (\%) & Non-smoker 859 (\%) & p value \\
\hline Complication & & & \\
\hline Heart failure & $27(3.6 \%)$ & $70(8.1 \%)$ & 0.019 \\
\hline Bleeding & $29(3.8 \%)$ & $38(4.4 \%)$ & ns \\
\hline Ventricular arrhythmia & $1(0.1 \%)$ & $4(0.5 \%)$ & ns \\
\hline Mortality & & & \\
\hline During admission & $24(3.2 \%)$ & $19(2.2 \%)$ & ns \\
\hline One Month & $36(4.7 \%)$ & $30(3.5 \%)$ & ns \\
\hline Six Month & $49(6.5 \%)$ & $49(6.5 \%)$ & ns \\
\hline One-year & $49(6.5 \%)$ & $67(7.8 \%)$ & ns \\
\hline
\end{tabular}

ns: Non-Significant.

Table 5: In-hospital complications and Mortality rate during admission, at onemonth, six-months, and one-year. inflammation, increase in plasma fibrinogen, enhanced platelet aggregation, catecholamine release and increase in heart rate and arterial blood pressure, vasoconstriction, and reduction in myocardial oxygen delivery [4-7,20-22]. "Smoker's paradox" describes the observations that smokers experience decreased mortality when they sustain NSTEACS or STEMI, or when they undergo percutaneous coronary intervention (PCI) compared with non-smokers. It is postulated that this may be due to the younger age and less comorbid disease in smokers rather than a benefit of smoking [23,24]. Other explanations include higher incidence of right coronary artery involvement and non-anterior wall MI, with potentially less incidence of life threatening ventricular arrhythmias and LV systolic dysfunction compared with LAD involvement and anterior wall MI. Moreover, smokers have a higher incidence of hypercoagulable state than non-smokers and this may lead to acute coronary thrombosis in the presence of less severe atherosclerosis thus predicting a better response to thrombolytic therapy [25]. Registries and clinical studies have found a significantly lower in-hospital mortality in acute MI and NSTEACS among smokers than non-smokers $[26,27]$. The term "smoker's paradox" was coined in the thrombolysis era when the use of fibrinolytic agents was the main strategy for STEMI reperfusion, and the high thrombogenicity state in smokers might have predicted a more favorable response to fibrinolysis [28]. However, this response was not confirmed by all thrombolysis trials, such as the GUSTO-1 trial which did not find any difference in the prevalence of thrombi or residual stenosis between smokers and non-smoker receiving thrombolysis [29]. In the contemporary era of primary PCI the studies are less supportive of the presence of this paradox when correction for differences in baseline variables was considered [30,31]. The absence of smoker's paradox that we observed in our study was similar to other more recent studies that showed a similar 1 -year crude mortality among smokers and non-smokers with ACS. Furthermore, some studies demonstrated a significant mortality excess (in the adjusted analysis) among smokers vs. non-smokers supporting the unfavorable effect of current smoking at baseline [32]. Absence of the paradox was also confirmed in STEMI patients undergoing primary PCI suggesting that the possible existence of a smoker's paradox does not extend into the invasive era [33]. Our study is a contemporary one where the majority of STEMI patients undergo primary PCI with an almost non-existing role for thrombolysis in the participating hospitals, and $60-70 \%$ of NSTEACS patients undergo coronary angiography and coronary revascularization. Absence of smoker's paradox; despite younger age and better clinical profile of smokers; strengthens the notion that smoking per se adversely affects the atherosclerotic disease severity, despite the fact that a minority of smokers in quit smoking after sustaining ACS [34]. The increasing frequency of studies refuting "smoker's paradox" during the last decade supports the argument that the paradox was due to confounding factors that were not adjusted for. Thus, the use of the term "smoker's paradox" itself does not seem to be fully justified and it would be wise to encourage smoking cessation rather than relying on the "positive effects" of the so-called paradox $[23,30,31,35]$. The present study has few limitations. We did not evaluate the clinical, angiographic or mortality data according to the number of cigarettes smoked or number of years of smoking. This may have had some influence on characterization of the patient groups and assessment of prognosis. In addition, patients who died before arrival in the hospital were not included, which may also have affected some of the results obtained. It is estimated that the form of presentation of MI in around $20 \%$ of patients is sudden death, which is also associated with smoking. Thus, many smokers may have died before being admitted and only those with better prognosis surviving. The hospitals that participated in the study were private and university medical centers 
Citation: Saleh A (2016) Absence of Smoker's Paradox in Middle Eastern Patients with Acute Coronary Syndrome. J Vasc Med Surg 4: 290. doi: 10.4172/2329-6925.1000290

with high accessibility to catheterization and thus the study does not reflect the care of ACS at a national level. Future studies involving a larger number of patients are needed to confirm our findings.

\section{Conclusions}

Despite the younger age and less prevalence of comorbid diseases, smokers in Jordan who were admitted with ACS did not have better outcome during the index admission and up to 1 year of follow up compare with non-smokers. Thus, in our population we didn't find a real "smoker's paradox", and the use of this term should be avoided. Smoking in the Middle East is a major cardiovascular risk factor, and should be a central target in primary and secondary prevention of atherosclerotic disease.

\section{References}

1. Baua RS, Ambrose JA (2013) Mechanisms of Coronary Thrombosis in Cigarette Smoke Exposure. Arterioscler Thromb Vasc Biology 33: 1460-1467.

2. Perk J, De Backer G, Gohlke H, Graham I, Reiner Z, et al. (2012) European Guidelines on cardiovascular disease prevention in clinical practice (version 2012): The Fifth Joint Task Force of the European Society of Cardiology and Other Societies on Cardiovascular Disease Prevention in Clinical Practice (constituted by representatives of nine societies and by invited experts). Eur J Prevent Cardiol 19: 4 585-667.

3. Chaudhry R, Chaudhry FA, Huynh T, Lader E, Rashid S, et al. (2010) Effect of smoking on age at the time of coronary artery bypass graft surgery: baseline data results from the ROSETTA-CABG registry. Heart Asia 2: 1 48-51.

4. Newby BA, Wright RA, Labinjoh C, Ludlam CA, Fox KAA, et al. (2014) Endothelial dysfunction, impaired endogenous fibrinolysis, and cigarette smoking A Mechanism for arterial thrombosis and myocardial infarction. Circ Res 114: 1852-1866.

5. Fearon IM, Acheampong DO, Bishop E (2012) Modification of Smoke Toxican Yields Alters the Effects of Cigarette Smoke Extracts on Endothelial Migration: An in vitro study using a cardiovascular disease model. International Journal of Toxicology 31: 572-583.

6. Buyukhatipoglu $\mathrm{H}$, Tiryaki $\mathrm{O}$, Usalan $\mathrm{C}$ (2009) Impaired fibrinolytic and blunted nitric oxide response to phlebotomy in cigarette smoking healthy blood donors. Journal of International Medical Research 37: 674-679.

7. Messner B, Bernhard D (2014) Smoking and cardiovascular disease: Mechanisms of endothelial dysfunction and early atherogenesis. Arterioscler Thromb Vasc Bio 34: 3 509-515.

8. Barbash GI, Reiner J, White HD , Woodlief LH, Topol EJ, et al. (1995) Evaluation of paradoxic beneficial effects of smoking in patients receiving thrombolytic therapy for acute myocardial infarction: mechanism of the "smoker's paradox" from the GUSTO-I trial, with angiographic insights. Global utilization of streptokinase and tissue plasminogen activator for occluded coronary arteries. J Am Coll Cardiol 26: 1222-1229.

9. Aune E, Roislien J, Mathisen M, Thelle DS, Otterstad JE (2011) The "smoker's paradox" in patients with acute coronary syndrome: a systematic review. BMC Med 9: 97

10. Aune E, Endresen K, Roislien J, Hjelmesaeth J, Otterstad JE (2010) The effect of tobacco smoking and treatment strategy on the one-year mortality of patients with acute non-ST-segment elevation myocardial infarction. BMC Cardiovasc Disord 10: 59-63.

11. Himbert D, Juliard JM, Golmard JK. (2001) Revision of the "smoker's paradox": smoking is not a good prognostic factor immediately after myocardial infarction. Arch Mal Coeur Vaiss 94: 262-268.

12. Andrikopoulos GK, Richter DJ, Dilaveris PE, Toutouzas PK, Chimonas ET, et al. (2001) In-hospital mortality of habitual cigarette smokers after acute myocardial infarction: the "smoker's paradox" in a countrywide study. Eur Heart J 22: 776-84.

13. Chen KY, Rha SW, Li YJ ,Choi CU, Oh DJ, et al. (2012) Smoker's paradox' in young patients with acute myocardial infarction. Clin Exp Pharmacol Physiol 39: 630-635.

14. Oyen VH, Berger N, Nusselder W, Charafeddine R, Demarest S, et al. (2014) The effect of smoking on the duration of life with and without disability, Belgium 1997-2011. BMC Public Health 14: 723.
15. Hammoudeh A, Izraiq M, Ismail $Y$, Tabbalat $R$, Hamdan $H$, et al. (2007) Utilization of reperfusion therapy in the Myocardial Infarction Triggers and Onset in JoRdan (MINTOR) Study. Int J Cardiol 122: 156-157.

16. Saleh A, Hammoudeh AJ, Hamam I, Khader YS, Nammas A, et al. (2012) Prevalence and impact on prognosis of glucometabolic states in a Middle Eastern country: The GLucometabolic abnOrmalities in patients with acute coronaRY syndrome in Jordan (GLORY) Study. International Journal of Diabetes in Developing Countries 32: 37-42.

17. Hammoudeh A, Alhaddad I (2009) Triggers and the onset of acute myocardial infarction. Cardiology in Review 17: 270-274

18. Hammoudeh AJ, Izraiq M, Hamdan H, Tarawneh H (2008) High-sensitivity C-reactive protein is an independent predictor of future cardiovascular events in Middle Eastern patients with acute coronary syndrome. CRP and prognosis in acute coronary syndrome (CAPRIS study). Int J Atherosclerosis 3: 50-55.

19. El-Menyar A, Zubaid M, Shehab A, Asaad N, Al Suwaidi J, et al. (2011) Prevalence and impact of cardiovascular risk factors among patients presenting with acute coronary syndrome in the Middle East. Clin Cardiol 34: 51-58.

20. Heffernan KS, Karas RH, Patvardhan EA, Kuvin JT (2009) Endotheliumdependent vasodilation is associated with exercise capacity in smokers and non-smokers. Vasc Med 15: 119-125.

21. Guarino F, Cantarella G, Caruso M, Russo C (2011) Endothelial activation and injury by cigarette smoke exposure. J Biol Regul Homeost Agents 25: 259-268.

22. Doonan RJ, Hausvater A, Scallan C, Mikhailidis DP, Pilote L, et al. (2010)The effect of smoking on arterial stiffness. Hypertens Res 33: 398-410.

23. Meseguer E, Labreuche J, Gonzalez-Valcarcel J (2014) The Smoking Paradox: Impact of Smoking on Recanalization in the Setting of Intra-Arterial Thrombolysis. Cerebrovasc Dis Extra 4: 84-91.

24. Rakowski T, Siudak Z, Dziewierz A, Dubiel JS, Dudek D (2012) Impact of smoking status on outcome in patients with ST-segment elevation myocardial infarction treated with primary percutaneous coronary intervention. J Thromb Thrombolysis 34: 397-403.

25. Nielsen VG, Hafner DT, Steinbrenner EB (2013) Can divergent plasminantiplasmin-carbon monoxide interactions in young, healthy tobacco smokers explain the 'smoker's paradox'?. Blood Coagul Fibrinolysis 24: 381-385.

26. Addad F, Dridi Z, Jemmali M, Mzoughi K, Hassine M, et al. (2010) "Smoker's paradox" and reperfusion's strategy in acute myocardial infarction. Ann Cardio Angeiol 59: 183-189.

27. Leung S, Gallup D, Mahaffey KW, Cohen M, Langer A, et al. (2008) SYNERGY Trial Investigators. Smoking status and antithrombin therapy in patients with nonST-segment elevation acute coronary syndrome. Am Heart J 156: 177-184

28. Barua RS, Sy F, Srikanth S, Huang G, Javed U, et al. (2010) Acute cigarette smoke exposure reduces clot lysis--association between altered fibrin architecture and the response to t-PA. Thromb Res 126: 426-430.

29. Kievit PC, Brouwer MA, Veen G, Aengevaeren WR, Verheugt FW (2009) The smoker's paradox after successful fibrinolysis: reduced risk of reocclusion bu no improved long-term cardiac outcome. J Thromb Thrombolysis 27: 385-393.

30. Gaspar A, Nabalis S, Rocha S, Torres M, Pinto J (2009) Smoking in acute coronary syndromes - the "smoker's paradox" revisited. Rev Port Cardiol 28 425-437.

31. De Luca G, Parodi G, Sciagrà R, Bellandi B, Correia A, et al. (2014) Smoking and infarct size among STEMI patients undergoing primary angioplasty. Atherosclerosis 233: 145-148.

32. Mahaffey KW, Yang Q, Pieper KS (2008) SYNERGY Trial Investigators Prediction of one-year survival in high-risk patients with acute coronary syndromes: results from the SYNERGY trial. J Gen Intern Med 23: 310-316.

33. Arbel Y, Matetzky S, Gavrielov-Yusim N (2014) Temporal trends in all-cause mortality of smokers versus non-smokers hospitalized with ST-segment elevation myocardial infarction. Int J Cardiol 176: 171-176.

34. Sochor O, Lennon RJ, Rodriguez-Escudero JP, Bresnahan JF (2015) Trends and Predictors of Smoking Cessation after Percutaneous Coronary Intervention. Am J Cardiol 115: 405-410.

35. Allahwala UK, Murphy JC, Nelson GI, Bhindi R (2013) Absence of a 'smoker's paradox' in field triaged ST-elevation myocardial infarction patients undergoing percutaneous coronary intervention. Cardiovasc Revasc Med 14: 213-217. 